\title{
Clinical relevance and therapeutic potential of angiopoietin-like protein 4 in hepatocellular carcinoma
}

\author{
Kevin Tak-Pan $\mathrm{Ng}^{1}$, Aimin Xu², Qiao Cheng ${ }^{1}$, Dong Yong Guo ${ }^{1}$, Zophia Xue-Hui Lim', Chris Kin-Wai Sun ${ }^{1}$,
} Jeffrey Hon-Sing Fung ${ }^{1}$, Ronnie Tung-Ping Poon', Sheung Tat Fan ${ }^{1}$, Chung Mau Lo ${ }^{1}$ and Kwan Man ${ }^{1 *}$

\begin{abstract}
Background: Development of novel adjuvant therapy to eradicate tumor angiogenesis and metastasis is a pressing need for patients with advanced hepatocellular carcinoma (HCC). We aimed to investigate the clinical relevance and therapeutic potential of angiopoietin-like 4 (ANGPTL4) in HCC.

Methods: ANGPTL4 mRNA levels in tumor and non-tumor liver tissues of HCC patients were analyzed to investigate its clinical relevance. The mechanisms of deregulation of ANGPTL4 in HCC were studied by copy number variation (CNV) and CpG methylation analyses. The orthotopic liver tumor nude mice model was applied using a human metastatic cell line. ANGPTL4-overexpressing adenovirus (Ad-ANGPTL4) was injected via portal vein to investigate its anti-tumorigenic and anti-metastatic potentials.

Results: HCC tissues expressed significantly lower levels of ANGPTL4 mRNA than non-tumor tissues. The copy number of ANGPTL4 gene in tumor tissues was significantly lower than in non-tumor tissues of HCC patients. Higher frequency of methylation of CPG sites of ANGPTL4 promoter was detected in tumor tissues compared to non-tumor tissues. Downregulation of ANGPTL4 mRNA in HCC was significantly associated with advanced tumor stage, presence of venous infiltration, poor differentiation, higher AFP level, appearance of tumor recurrence, and poor postoperative overall and disease-free survivals of HCC patients. Treatment with Ad-ANGPTL4 significantly inhibited the in vivo tumor growth, invasiveness and metastasis by promoting tumoral apoptosis, inhibiting tumoral angiogenesis and motility, and suppressing tumor-favorable microenvironment. Moreover, administration of recombinant ANGPTL4 protein suppressed the motility of HCC cells and altered the secretion profile of cytokines from macrophages.
\end{abstract}

Conclusion: ANGPTL4 is a diagnostic and prognostic biomarker for HCC patients and a potential therapeutic agent to suppress HCC growth, angiogenesis and metastasis.

Keywords: Hepatocellular carcinoma, Angiopoietin-like 4, Angiogenesis, Metastasis, Therapeutic

\section{Background}

Hepatocellular carcinoma (HCC) is one of the most malignant tumors and the fourth leading cause of cancerrelated death worldwide [1]. Surgical operations including liver resection and liver transplantation are effectively curative treatments for patients with early stage of HCC,

\footnotetext{
* Correspondence: kwanman@hku.hk

'Department of Surgery and Centre for Cancer Research, LKS Faculty of Medicine, The University of Hong Kong, Room L9-55, Li Ka Shing Faculty of Medicine Building, 21 Sassoon Road, Pokfulam, Hong Kong, SAR, China
} Full list of author information is available at the end of the article but patients with advanced HCC cannot be beneficial from it. In addition to clinical shortcoming of chemoresistance of HCC causing ineffective implementation of systemic chemotherapy and targeted therapy, patients with advanced HCC have been often suffering from poor prognosis [2-5]. Therefore, searching for novel adjuvant therapies targeting $\mathrm{HCC}$ progression and metastasis is a pressing need.

Angiopoietin-like 4 (ANGPTL4) protein, a secreted protein, is one of the members of angiopoietin (ANG)relating family which shares very high similarity to the 
structure of ANG family. ANGPTL4 protein contains a highly hydrophobic signal peptide, an N-terminal coiledcoil domain and a C-terminal fibrinogen-like domain [6]. ANGPTL4 is expressed highly in numerous organs including adipose tissue, liver, heart and small intestine [7-9]. Moreover, ANGPTL4 can be stimulated by inflammatory and hypoxic conditions $[6,7,10]$. ANGPTL4 exerts multifunctional roles such as glucose and lipid metabolisms, inflammation, differentiation, angiogenesis, and tumorigenesis [6,7]. The roles of ANGPTL4 in human cancers are controversial. Overexpression of ANGPTL4 can promote tumorigenesis, tumor invasion, angiogenesis, anoikis resistance and metastasis [11-15]. On the other hand, ANGPTL4 is an anti-metastatic protein on tumor cells through inhibition of vascular permeability, motility and invasiveness [16]. The clinical implications and functional roles of ANGPTL4 in HCC so far are not well defined. One study has demonstrated that high level of serum ANGPTL4 protein in HCC patients is significantly associated with liver cirrhosis, higher histological grade and intrahepatic metastasis [17]. However, a recent study demonstrated that the expression levels of ANGPTL4 protein in tumor tissues are significantly lower than in non-tumor tissues of HCC patients [18]. Our previous study has demonstrated that ANGPTL4 plays important roles in regulating glucose and lipid metabolisms of the liver in mice [19]. In this study, we aimed to investigate the clinical relevance of ANGPTL4 in HCC patients and its therapeutic implication and underlying mechanisms on HCC growth, angiogenesis and metastasis.

\section{Results}

\section{Underexpression of ANGPTL4 in HCC}

Quantitative RT-PCR was employed to study the expression levels of ANGPTL4 mRNA in paired tumor and non-tumor liver tissues from 110 HCC patients and in liver tissues from 26 healthy donors. The average expression level (log2 base) of ANGPTL4 mRNA among tumor, non-tumor and healthy donor liver tissues were 5.98, 7.13 and 6.98 respectively (Figure 1A). The tumor tissues expressed a 2.2-fold lower level of ANGPTL4 mRNA than non-tumor tissues of HCC patients in average, which was statistically significant using unpaired and paired $\mathrm{t}$-tests (2-tailed unpaired $\mathrm{t}$-test, $p<0.0001$; 2-tailed paired t-test, $p<0.0001)$. There was no significant difference of ANGPTL4 mRNA between nontumor tissues and healthy liver tissues. Comparing paired tumor and non-tumor tissues of each HCC patients, $51.82 \%(57 / 110)$ of tumor tissues were found to have lower expression of ANGPTL4 mRNA while 16.36\% (18/110) of tumor tissues expressed higher ANGPTL4 mRNA (Figure 1B). The expression levels of ANGPTL4 mRNA in the $6 \mathrm{HCC}$ cell lines were lower than in MIHA cell line (Figure 1C). These data suggested that the expression of ANGPTL4 mRNA was commonly downregulated in HCC.
To understand the possible mechanism of downregulation of ANGPTL4 in HCC, copy number variation (CNV) analysis and CpG methylation analysis by pyrosequencing were performed in 40 pairs of tumor and non-tumor DNA samples from HCC patients. The relative ANGPTL4 CNV value in tumor tissues of HCC patients was determined to be significantly lower than in non-tumor tissues $(p=0.025$, unpaired two-tailed t-test, Figure 1D). The result from pyrosequencing showed that there were 5 to $20 \%$ of positive methylations detected among the $5 \mathrm{CpG}$ sites of the ANGPTL4 promoter in tumor tissues while there was no positive methylation detected in all non-tumor tissues (Figure 1E). These data suggested that hypermethylation of the promoter region of ANGPTL4 gene may be one of the mechanisms leading to downregulation of ANGPTL4 expression in HCC.

\section{Clinical relevance and prognostic values of ANGPTL4 in HCC}

Statistical analyses were performed to investigate the clinical relevance and prognostic potential of ANGPTL4 mRNA in HCC. Comparing the expression levels of ANGPTL4 mRNA between paired primary and recurred tumor tissues in 5 HCC patients, 4 recurred tumors $(80 \%)$ were found to have significantly lower levels of ANGPTL4 mRNA than their matched primary tumors (Figure 1F). Statistical analyses showed that either higher degree of downregulation ANGPTL4 mRNA or lower expression level of ANGPTL4 mRNA in tumor tissues of HCC patients were significantly associated with presence of venous infiltration, poor differentiation, advanced pathologic tumor-node-metastasis (pTNM) stage and presence of recurrence (Table 1). Moreover, correlation analysis by Pearson coefficient test showed that the expression of ANGPTL4 mRNA was negatively correlated with serum alpha fetoprotein (AFP) level, and overall and disease-free survivals (Table 2). The above result suggested that the degree of downregulation was positively correlated with advanced stage of $\mathrm{HCC}$ and poor survivals of $\mathrm{HCC}$ patients. The expression level of ANGPTL4 mRNA in non-tumor tissues of HCC patients was not significantly associated with any clinical factors (Tables 1 and 2).

To obtain an optimal cutoff point for examining the prognostic value of ANGPTL4 mRNA in HCC patients, Receiver operating characteristic (ROC) curve was generated to analyze the sensitivity and 1-specificity using the value of $\Delta \Delta \Delta \operatorname{Ct}\left(A N G P T L 4_{\text {patient }}\right)$ to predict the $1^{\text {st }}$ year postoperative overall survival of HCC patients (Figure 2A). The under area of ROC curve was determined as 0.677. According to Youden index, the optimal cutoff value of $\Delta \Delta \triangle \mathrm{Ct}\left(\right.$ ANGPTL4 $\left._{\text {patient }}\right)$ among HCC patients was determined to be -1.585 . Sixty-seven $(60.90 \%)$ and 43 (39.09\%) HCC patients were defined as ANGPTL4 mRNA Non-downregulation group and Downregulation group. 


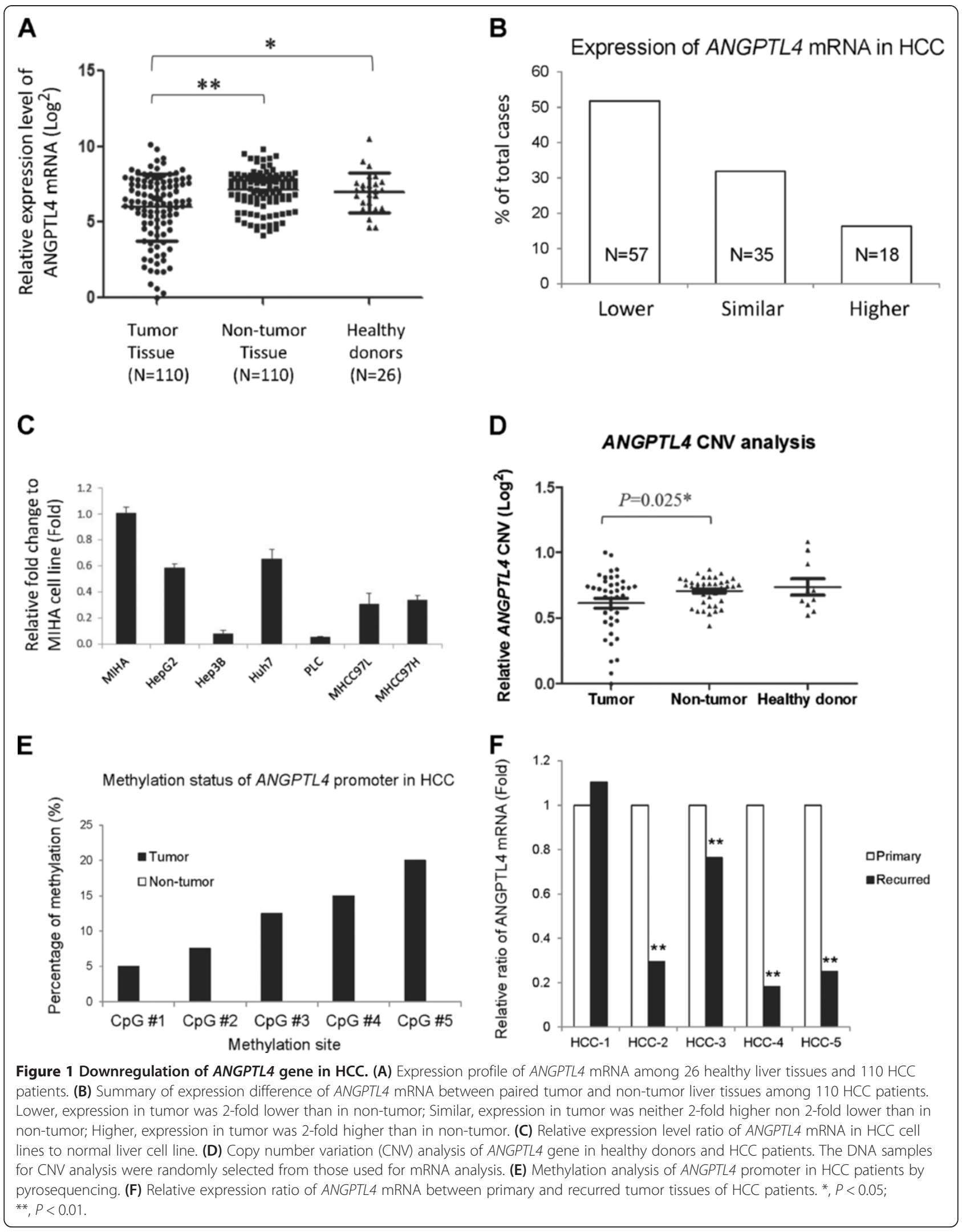


Table 1 Statistical analysis of ANGPTL4 mRNA with clinical factors of HCC patients using two-tailed T-test

\begin{tabular}{|c|c|c|c|c|c|c|c|}
\hline \multirow[b]{3}{*}{ Clinical factors } & \multirow[b]{3}{*}{ Number (n) } & \multicolumn{6}{|c|}{ ANGPTL4 mRNA in HCC patients } \\
\hline & & \multicolumn{2}{|c|}{ Tumor/non-tumor difference } & \multicolumn{2}{|c|}{ Tumor } & \multicolumn{2}{|c|}{ Non-tumor } \\
\hline & & Mean (Log2) & $P$ & Mean (Log2) & $p$ & Mean (Log2) & $p$ \\
\hline \multicolumn{8}{|l|}{ Sex } \\
\hline Male & 88 & -1.20 & 0.889 & 5.85 & 0.381 & 7.15 & 0.670 \\
\hline Female & 22 & -1.12 & & 6.32 & & 7.02 & \\
\hline \multicolumn{8}{|l|}{ Venous infiltration } \\
\hline Absent & 51 & -0.67 & $0.023^{*}$ & 6.51 & $0.012^{*}$ & 7.18 & 0.692 \\
\hline Present & 59 & -1.63 & & 5.45 & & 7.08 & \\
\hline \multicolumn{8}{|l|}{ Differentiation $^{a}$} \\
\hline Moderately or well & 87 & -0.82 & $0.000^{* * *}$ & 6.21 & $0.013^{*}$ & 7.17 & 0.639 \\
\hline Undifferentiated or poorly & 18 & -3.21 & & 4.80 & & 7.01 & \\
\hline \multicolumn{8}{|l|}{ pTNM staging $^{a}$} \\
\hline Early stage & 34 & -0.35 & $0.007^{* *}$ & 6.67 & $0.025^{*}$ & 7.04 & 0.646 \\
\hline Advanced stage & 75 & -1.56 & & 5.66 & & 7.16 & \\
\hline \multicolumn{8}{|l|}{ Cirrhosis $^{a}$} \\
\hline No cirrhosis & 39 & -0.97 & 0.479 & 5.98 & 0.981 & 6.98 & 0.382 \\
\hline Cirrhosis & 69 & -1.29 & & 5.97 & & 7.20 & \\
\hline \multicolumn{8}{|l|}{ Recurrence } \\
\hline No recurrence & 49 & -0.69 & $0.035^{*}$ & 6.58 & $0.006^{* *}$ & 7.20 & 0.577 \\
\hline Recurrence & 61 & -1.58 & & 5.43 & & 7.07 & \\
\hline \multicolumn{8}{|l|}{ Hepatitis B surface antigen } \\
\hline Negative & 16 & -0.99 & 0.700 & 5.53 & 0.429 & 6.61 & 0.080 \\
\hline Positive & 94 & -1.22 & & 6.01 & & 7.22 & \\
\hline
\end{tabular}

Total number less than 110 due to missing data; ${ }^{*}, p<0.05 ;{ }^{* *}, p<0.01 ; * * *, p<0.001$.

Kaplan-Meier analysis illustrated that HCC patients in Downregulation group was significantly associated with poor overall survival rate $(p=0.003$, Figure $2 \mathrm{~B})$ and poor disease-free survival rate $(p=0.015$, Figure $2 C)$ of the patients after hepatectomy compared to patients in Non-downregulation group. The mean periods of postoperative overall and disease-free survivals for Downregulation group were 61.7 and 41.2 months, while for Non-downregulation group were 93.0 and 66.7 months. Univariable Cox regression hazard analysis showed that
ANGPTL4 mRNA was a significant prognostic biomarker for predicting postoperative overall and disease-free survivals of HCC patients (Table 3). The above results suggested that ANGPTL4 mRNA may be a prognostic biomarker for HCC patients after hepatectomy.

\section{ANGPTL4 suppressed HCC tumorigenesis and metastasis}

The therapeutic potential of ANGPTL4 treatment was examined in an orthotopic xenograft liver tumor model in mice. The result showed that injection of Ad-ANGPTL4

Table 2 Correlation analysis of ANGPTL4 mRNA with clinical factors of HCC patients

\begin{tabular}{|c|c|c|c|c|c|c|c|}
\hline \multirow[b]{3}{*}{ Clinical factors } & \multirow[b]{3}{*}{ Number (n) } & \multicolumn{6}{|c|}{ ANGPTL4 mRNA in HCC patients } \\
\hline & & \multicolumn{2}{|c|}{ Tumor/non-tumor difference } & \multicolumn{2}{|c|}{ Tumor } & \multicolumn{2}{|c|}{ Non-tumor } \\
\hline & & $\begin{array}{c}\text { Pearson } \\
\text { correlation (R) }\end{array}$ & $P$ & $\begin{array}{c}\text { Pearson } \\
\text { correlation (R) }\end{array}$ & $p$ & $\begin{array}{c}\text { Pearson } \\
\text { correlation (R) }\end{array}$ & $p$ \\
\hline Age (Year) & 110 & -0.039 & 0.682 & -0.084 & 0.382 & -0.038 & 0.693 \\
\hline AFP level (mg/ml) & 110 & -0.276 & $0.004^{* *}$ & -0.263 & $0.005^{* *}$ & 0.051 & 0.593 \\
\hline Tumor size $^{\mathrm{a}}(\mathrm{cm})$ & 95 & 0.017 & 0.871 & 0.077 & 0.456 & 0.186 & 0.071 \\
\hline Overall survival (Month) & 110 & 0.289 & $0.002^{* *}$ & 0.230 & $0.016^{*}$ & -0.123 & 0.201 \\
\hline Disease-free survival (Month) ${ }^{\mathbf{b}}$ & 109 & 0.241 & $0.012^{*}$ & 0.266 & $0.005^{* *}$ & -0.032 & 0.740 \\
\hline
\end{tabular}

${ }^{\mathrm{a}}$ Total number less than 110 due to missing data. ${ }^{\mathrm{b}}$ Total number less than 110 due to one patients was out of selection; ${ }^{*}, p<0.05 ;{ }^{* *}, p<0.01$. 
Figure 2 Survival analyses of ANGPTL4 mRNA in HCC patients.

(A) Receiver operating characteristic (ROC) curve analysis of ANGPTL4 mRNA on predicting 1-year overall survival of HCC patients after liver resection. (B) Kaplan-Meier analysis of ANGPTL4 mRNA on predicting overall survival of HCC patients after hepatectomy. (C) Kaplan-Meier analysis of ANGPTL4 mRNA on predicting disease-free survival of HCC patients after hepatectomy. ${ }^{*}, P<0.05$; ${ }^{* *}, P<0.01$.

after orthotopic implantation of human liver tumor significantly hindered tumor formation from 3 weeks to 6 weeks (Figure 3A). The average tumor volume at week 6 was reduced by 11.6 folds after Ad-ANGPTL4 treatment compared to the control group (Figure 3B). Moreover, significant inhibitions of distant metastases including lung, abdominal and multi-organ metastases at week 6 were detected in Ad-ANGPTL4 treatment group compared to the control group (Figure 3C). Histological examination revealed that liver tumors in the control group exhibited progressive morphologies including disrupted encapsulation and infiltrated tumor thrombus, while in Ad-ANGPTL4 treatment group, most of the tumors were surround by intact capsules and without venous-infiltrated tumor thrombus (Figure 4A). Moreover, the non-tumor liver tissues remained normal after Ad-ANGPTL4 treatment (Figure 4A). Histological examination of consecutive lung tissue sections also confirmed a significant reduction of lung metastasis at week 5 after Ad-ANGPTL4 treatment compared to the control group (Figure 4A). Consistently, transmission electron microscopy analysis revealed that Ad-ANGPTL4 treatment disrupted the integrity of the tumor endothelial cells and suppressed the invasiveness of the tumor compared to the control group (Figure 4B). These date suggested that ANGPTL4 may be a potential therapeutic agent to suppress HCC growth and metastasis.

\section{Disease-free survival}

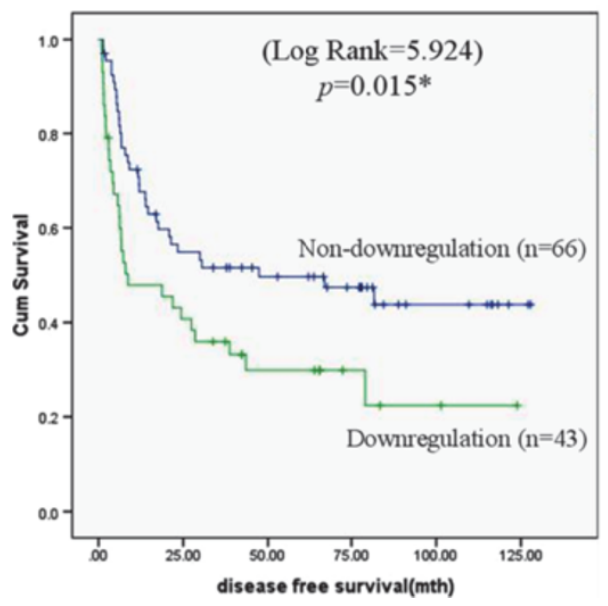

\section{ANGPTL4 promoted tumor apoptosis and inhibits tumor angiogenesis}

To understand the possible mechanisms of ANGPTL4 on suppressing HCC growth, its effects on apoptosis and angiogenesis of $\mathrm{HCC}$ were studied. The result showed that Ad-ANGPTL4 treatment significantly increased the number of intratumoral apoptotic cells by approximately 3 folds compared to the control group (Figure 5A). Moreover, administration of recombinant ANGPTL4 (rANGPTL4) protein could increase the activation of caspase 7 and 9, and downregulated the expression of anti-apoptotic protein Bcl2 (Figure 5D). These data suggested that ANGPTL4 could promote apoptosis of HCC cells. In order to study the effect of ANGPTL4 on angiogenesis of HCC, the intratumoral microvessel density (MVD) which indicates the formation of new vessels was determined by immunohistochemical staining of CD34 antibody. The result showed that Ad-ANGPTL4 treatment significantly decrease the MVD by 4 folds in tumor 
Table 3 Cox proportional hazard regression analysis of ANGPTL4 mRNA and clinicopathological parameters in relation to the overall and disease-free survivals of HCC patients after hepatectomy

\begin{tabular}{|c|c|c|c|c|}
\hline & \multicolumn{2}{|c|}{ Univariable analysis } & \multicolumn{2}{|c|}{ Multivariable analysis } \\
\hline & HR $(95 \% \mathrm{Cl})$ & $P$ & HR $(95 \% \mathrm{Cl})$ & $P$ \\
\hline \multicolumn{5}{|l|}{ 1. Overall survival } \\
\hline \multicolumn{5}{|l|}{ ANGPTL4 mRNA } \\
\hline Downregulation vs Non-downregulation & $2.39(1.33-4.27)$ & $0.003^{* *}$ & $1.48(0.81-2.72)$ & 0.204 \\
\hline \multicolumn{5}{|l|}{ pTNM staging } \\
\hline Advanced vs early & $5.37(2.25-12.81)$ & $0.000^{* * *}$ & 2.26(0.71-7.18) & 0.168 \\
\hline \multicolumn{5}{|l|}{ Venous infiltration } \\
\hline Presence $v s$ absence & $4.41(2.25-8.67)$ & $0.000^{* * *}$ & $2.11(0.88-5.09)$ & 0.096 \\
\hline \multicolumn{5}{|l|}{ AFP level } \\
\hline$>20 \mathrm{ng} / \mathrm{ml} v s \leq 20 \mathrm{ng} / \mathrm{ml}$ & $3.10(1.60-5.99)$ & $0.001^{* *}$ & $2.12(1.07-4.21)$ & $0.031^{*}$ \\
\hline \multicolumn{5}{|l|}{ 2. Disease-free survival } \\
\hline \multicolumn{5}{|l|}{ ANGPTL4 mRNA } \\
\hline Downregulation vs Non-downregulation & $1.83(1.12-2.99)$ & $0.017^{*}$ & $1.40(0.84-2.32)$ & 0.201 \\
\hline \multicolumn{5}{|l|}{ pTNM staging } \\
\hline Advanced vs early & $2.87(1.57-5.24)$ & $0.001^{* *}$ & 1.33(0.53-3.35) & 0.544 \\
\hline \multicolumn{5}{|l|}{ Venous infiltration } \\
\hline Presence $v$ s absence & $3.14(1.84-5.37)$ & $0.000^{* * *}$ & $2.36(1.06-5.26)$ & $0.036^{*}$ \\
\hline
\end{tabular}

compared to control group (Figure 5B). This suggested ANGPTL4 can suppress angiogenesis of HCC. Furthermore, Western blot analysis showed that Ad-ANGPTL4 treatment could inhibit the expression of VEGF protein and phosphorylation of Raf-MEK-Erk signaling pathway of $\mathrm{HCC}$ (Figure 5C). Administration of rANGPTL4 protein on HCC cells also inhibit the expression of VEGF and activation of Raf-MEK-Erk pathways (Figure 5D). These data suggested an anti-angiogenic effect of ANGPTL4 on HCC.

\section{ANGPTL4 suppressed the motility of HCC cells}

In order to understand the mechanism of ANGPTL4 on suppressing $\mathrm{HCC}$ metastasis, its effect on $\mathrm{HCC}$ motility was investigated. ROCK1 is an important player in regulating the motility and migration of cancer cells [20]. Western blot analysis showed that treatment of Ad-ANGPTL4 suppressed the expression of ROCK1 protein in tumor tissues compared to the control group (Figure 6A). In vitro experiment showed that administration of rANGPTL4 protein on HCC cell lines suppressed the their formation of polymerized stress fibers which indicated by F-actin staining (Figure 6B). Under scanning electronic microscopy, the formation of hair-like fiber structure of $\mathrm{Hep} 3 \mathrm{~B}$ and MHCC97L cells was suppressed after administration of rANGPTL4 protein (Figure 6C). Western blot analysis showed that rANGPTL4 protein decreased the expression of ROCK1 protein in MHCC97L cells (Figure 6D). These data suggested that ANGPTL4 could suppress the motility of HCC cells thereby reduce their metastatic ability.

\section{ANGPTL4 influenced tumor-microenvironment}

The ability to manipulate the microenvironment is one of the hallmarks of cancer to promote tumor progression, invasion and metastasis [21]. The effect of ANGPTL4 treatment on tumor-microenvironment was therefore studied from different aspects. Compared to the control group, the number of activated hepatic stellate cells (HSCs), revealed by immunohistochemical staining of $\alpha$-smooth muscle actin ( $\alpha$-SMA) protein, was significantly suppressed after Ad-ANGPTL4 treatment (Figure 7A). The number of infiltrated tumor-associated macrophages (TAMs) stained by anti-CD68 antibody in xenograft liver tumor was significantly reduced after Ad-ANGPTL4 treatment (Figure 7B). Western blot analysis showed that MMP-12 protein was down-regulated in Ad-ANGPTL4 treatment group compared to the control group (Figure $7 \mathrm{C}$ ). Administration of rANGPTL4 protein to mouse macrophage cell line altered the profile of secreted cytokines including up-regulations of CD30L, CD30T, CD40, CRG2, CTACK, CXCL16, eotaxin and L-selectin, and down-regulations of SDF-1 $\alpha$, TARC, TCA-3, TECK, TIMP-1, TNF $\alpha$ and STNFR1 (Figure 7D). These data suggested that ANGPTL4 can destroy the tumor-favorable microenvironment in HCC. 


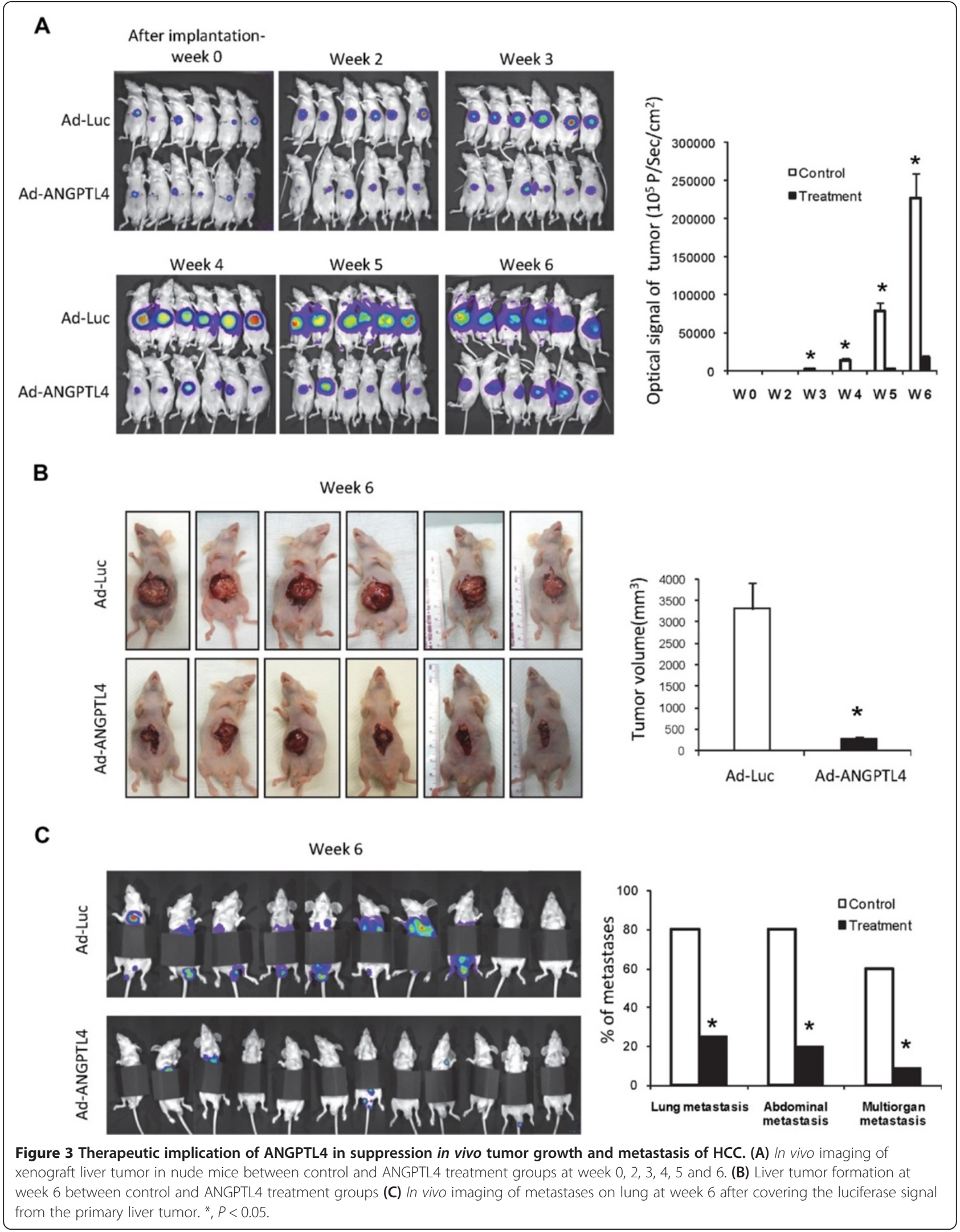




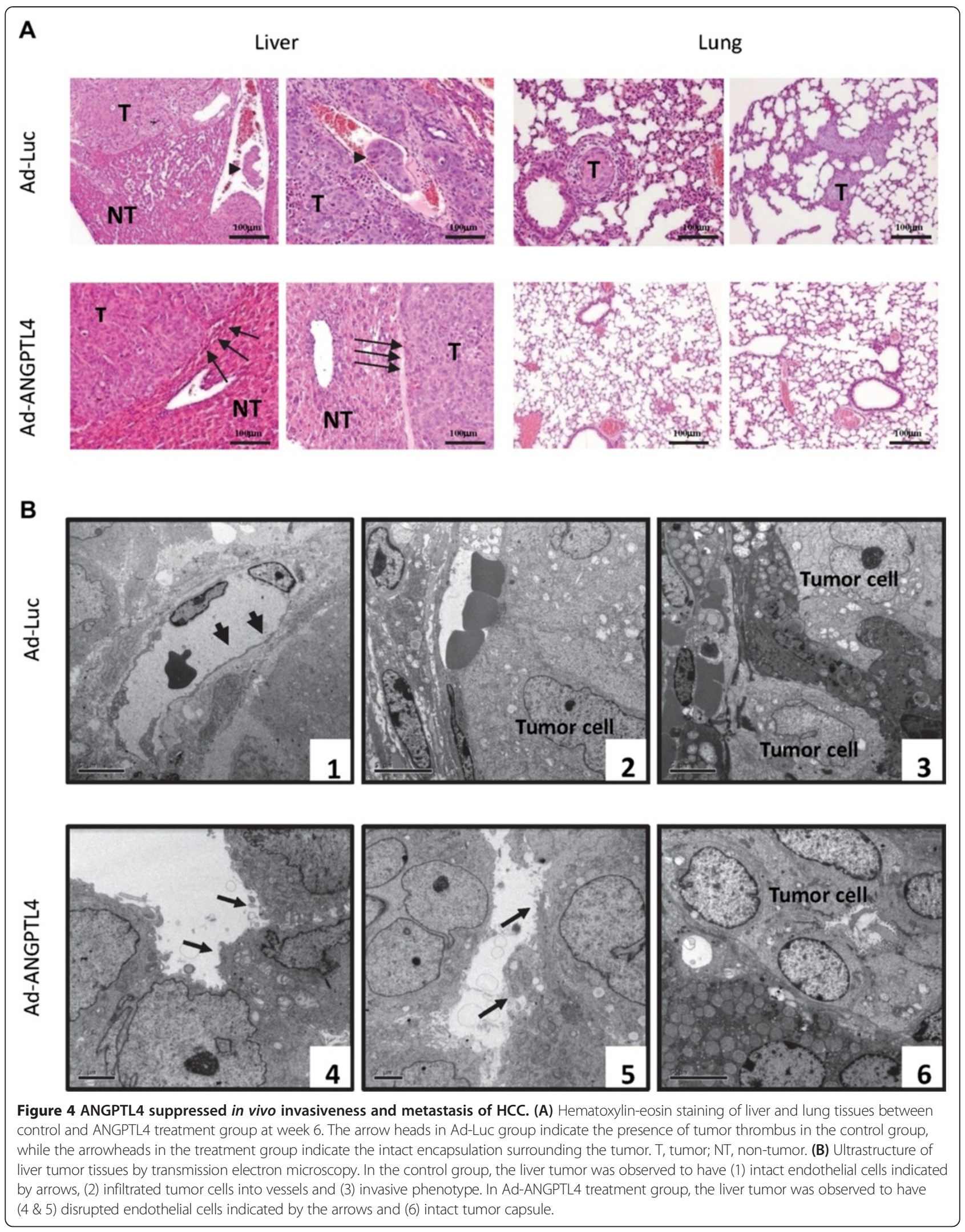




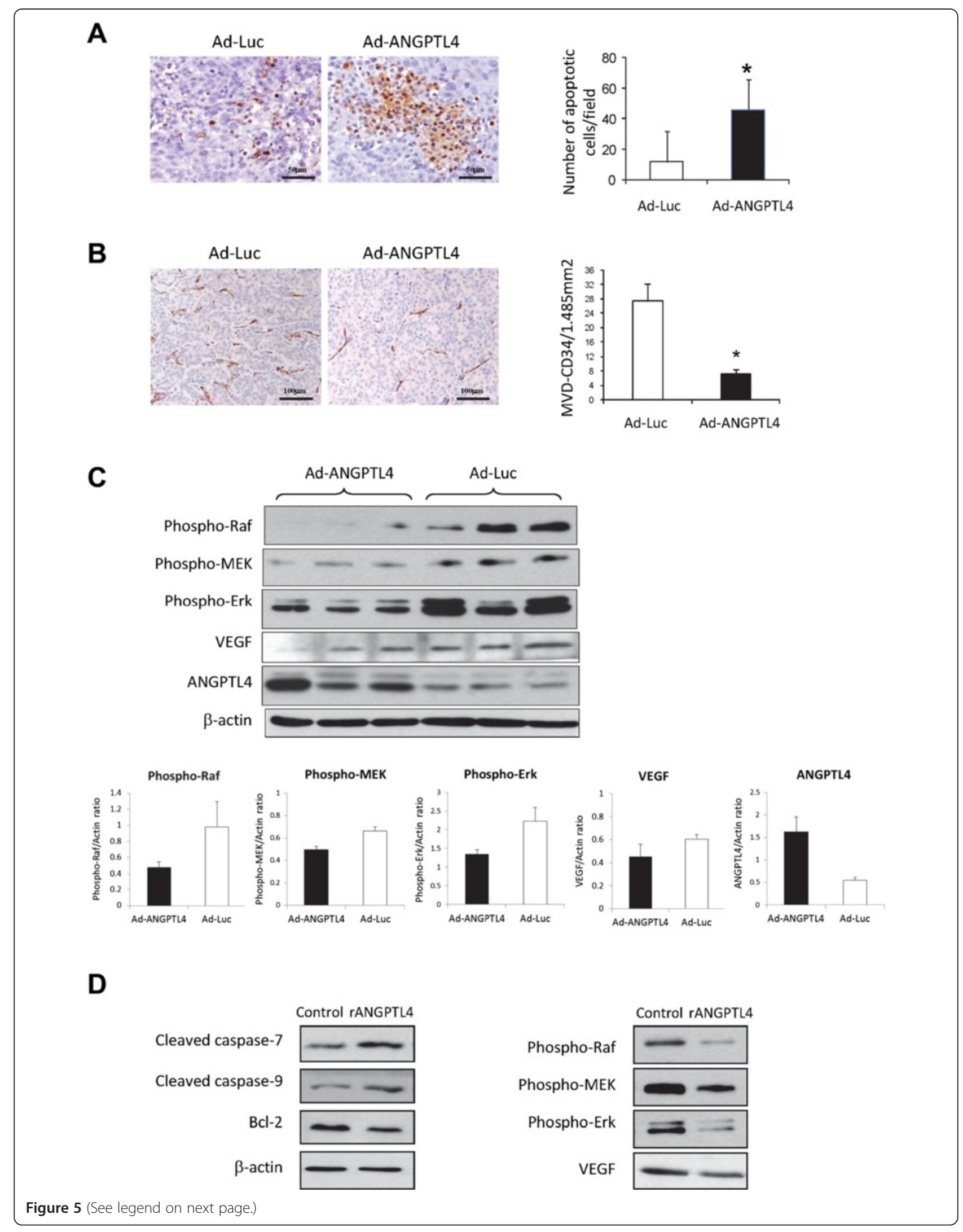


(See figure on previous page.)

Figure 5 ANGPTL4 promoted apoptosis and suppressed angiogenesis of HCC. (A) TUNEL assay on liver tumor tissues. (B) Determination of microvessel density (MVD) of liver tumor tissues by immunohistochemical staining using anti-CD34 antibody. (C) Western blot analysis of VEGF, phosphor-Raf, Phospho-MEK, Phospho-Erk, ANGPTL4 and beta-actin proteins in liver tumor tissues in Ad-ANGPTL4 and Ad-Luc groups. The average protein expression between Ad-ANGPTL4 and Ad-Luc group was quantified and summarized in the lower panel figures. (D) Western blot analysis of proteins in MHCC97L cells after treating with rNGPTL4 protein. ${ }^{*}, P<0.05$.

\section{Discussion}

There have been several studies suggesting that ANGPTL4 is deregulated in cancers, whether it is elevated or suppressed in tumor is dependent on the types and the contexts of cancers [6]. The expression profile of ANGPTL4 in HCC patients is diverse so far. One study has demonstrated that serum ANGPTL4 protein in HCC patients is higher than in chronic hepatitis $\mathrm{B}$ patients and normal controls [17]. However the study did not indicate whether the expression of ANGPTL4 in HCC tissues is deregulated or not [17]. Zhu has demonstrated that ANGPTL4 protein is upregulated in tumor tissues of HCC patients compared to normal liver tissue, but only $2 \mathrm{HCC}$ samples were examined on tissue arrays [13]. Another study has found that ANGPTL4 protein in carcinoma tissues is significantly lower than in adjacent tissues of HCC patients [18]. In our study, the overall expression level of ANGPTL4 mRNA in tumor tissues of HCC patients was lower than non-tumor tissues and healthy liver tissues. Moreover, the number of patients having lower ANGPTL4 mRNA expression in HCC was greater than the number of having higher ANGPTL4 mRNA expression in HCC. Furthermore, the relative expression levels of ANGPTL4 mRNA in $6 \mathrm{HCC}$ cell lines were lower than the normal liver cell line. Therefore, our above evidences suggested that ANGPTL4 mRNA is underexpressed in HCC. ANGPTL4 gene locates in chromosome 19p13.3. Several lines of evidences have proved that chromosome $19 \mathrm{p}$ is one of the most frequently deleted chromosomal regions in HCC [22-24]. Moreover, a finding in gastric cancer has suggested that methylation is a mechanism of silencing ANGPTL4 gene leading to tumor development [25]. Methylation of ANGPTL4 gene has also been found in primary breast cancer [26]. Our $\mathrm{CNV}$ and methylation analyses demonstrated that lower copy number of ANGPTL4 gene and presence of methylation in the promoter of ANGPTL4 gene might contribute to decreased expression of ANGPTL4 gene in HCC.

Downregulation of ANGPTL4 mRNA in HCC was found to be significantly associated with poor prognosis after curative surgery. The clinicopathological parameters of the patients with higher degree of downregulation of ANGPTL4 were significantly associated with higher malignancy of HCC including advanced HCC stage, presence of venous infiltration, poor differentiation, higher AFP level and appearance of postoperative tumor recurrence. One of the functions of ANGPTL4 is involving in regulating cell differentiation [7]. Our result demonstrated that patients with undifferentiated or poorly differentiated HCC had significantly lower levels of ANGPTL4 mRNA in tumor tissues (Table 1), suggesting that deregulation of ANGPTL4 mRNA may indicate the status of tumor differentiation. In addition, most of the recurred HCC tumors expressed lower levels of ANGPTL4 mRNA than the primary tumors. These above results indicated that the expression level of ANGPTL4 mRNA in HCC is reversely correlated with tumor malignancy. Most importantly, patients with downregulation of ANGPTL4 mRNA in HCC were significantly associated with poor postoperative overall and disease-free survivals. Therefore, our data suggested that ANGPTL4 mRNA may be a potential diagnostic and prognostic biomarker for HCC patients.

ANGPTL4 exhibits both pro-tumorigenic and antitumorigenic properties depending on the tissue contexts and the status of posttranslational modifications [6]. Overexpression of ANGPTL4 can inhibit the motility, invasiveness and metastasis of Lewis lung carcinoma and mouse skin cancer cells [16]. However, many studies have suggested that ANGPTL4 can promote tumor growth, angiogenesis, invasion and metastasis [11-15]. A study in HCC has showed that ANGPTL4 promotes tumor migration and metastases [17]. Our study demonstrated that treatment with Ad-ANGPTL4 significantly suppressed not only the in vivo growth, angiogenesis and invasiveness, but also the extrahepatic multiorgan metastases of HCC. In addition, treatment with Ad-ANGPTL4 did not cause potential deleterious side effects on the liver tissues. These results suggested that ANGPTL4 may be a potential therapeutic agent for treatment of HCC.

Our study demonstrated several mechanisms of ANGPTL4 in suppressing tumor progression, invasion and metastasis of HCC. First, overexpression of ANGPTL4 suppressed tumor growth through enhancing apoptosis of tumor cells, indicating that suppression of ANGPTL4 in HCC may be a way to escape from apoptosis. Second, overexpression of ANGPTL4 could suppress the invasiveness of HCC cells by restraining its motility through suppression the expression of ROCK1 and formation of polymerized stress fibers. ANGPTL4 is an important regulator involved in vascular permeability and angiogenesis $[6,7]$. In this study, Ad-ANGPTL4 treatment significantly suppressed the formation of new vessels in the tumor through repressing the expression of angiogenic factor VEGF and suppressing the activation of Raf-MEK-Erk 
A
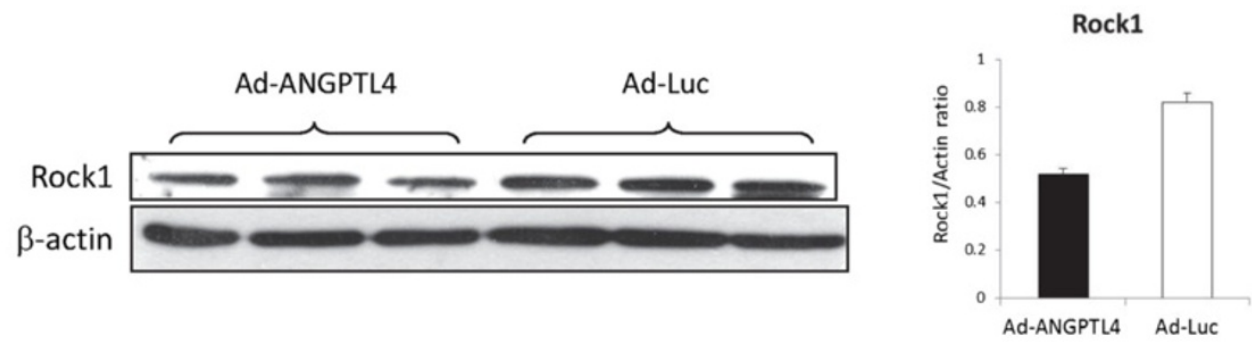

B
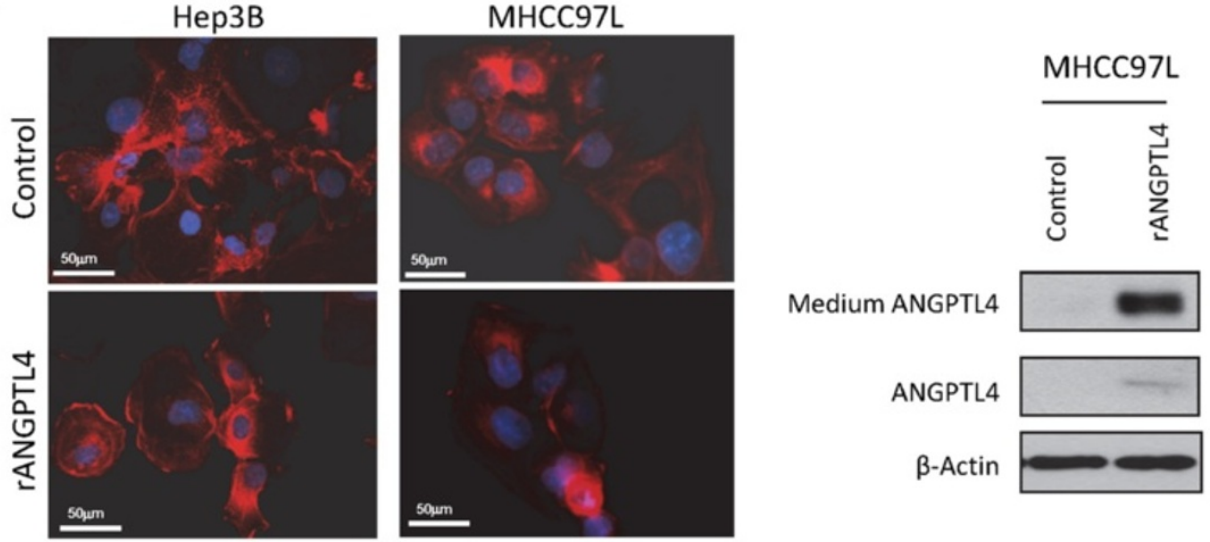

Medium ANGPTL4

ANGPTL4

B-Actin

MHCC97L
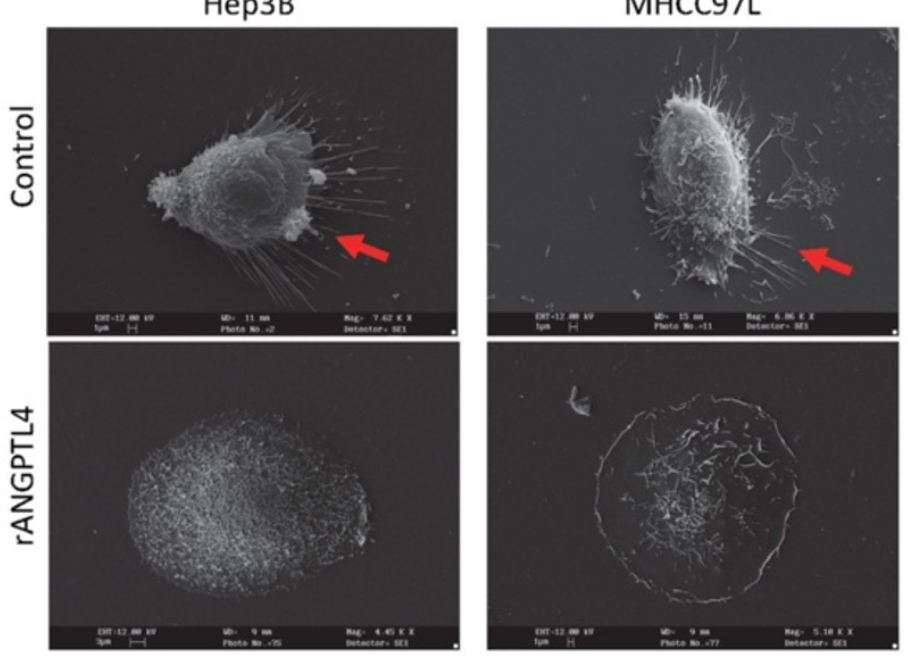

D

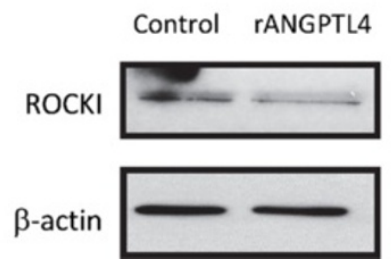

Figure 6 (See legend on next page.) 
(See figure on previous page.)

Figure 6 ANGPTL4 suppressed the motility of HCC. (A) Western blot analysis of ROCK1 protein in tumor xenograft between Ad-ANGPTL4 treatment group and the Ad-Luc control group. Up-regulation of ANGPTL4 protein by Ad-ANGPTL4 treatment was validated in Figure 5C. (B) The effect of rANGPTL4 protein on formation of polymerized stress fibers in HCC cells, indicated by immunostaining of F-actin using rhodamine-phalloidin probe. Red color, F-actin signal; Blue color, nucleic staining by DAPI. The level of ANGPTL4 protein in cells and medium was determined by Western blot analysis (C) Scanning electron microscopy of the morphology of HCC cells after administration of RANGPTL4 protein. Red arrows indicate the formation of extracellular "hair-like" stress fibers. (D) Western blot analysis of ROCK1 protein in MHCC97L cells after administration of rANGPTL4 protein.

signaling pathway, suggesting an anti-angiogenic effect of ANGPTL4 on HCC. Angiogenesis which is one of the hallmarks of cancer for obtaining oxygen and nutrients and eliminating wastes is critical for tumorigenesis and metastasis processes [21]. Targeted therapy on inhibiting angiogenesis of $\mathrm{HCC}$ has increasingly become one of the important therapeutic strategies in treating patients with advanced HCC $[27,28]$. Modulating tumor microenvironment to promote tumor progression, invasion and metastasis is one of the hallmarks of cancer [21]. Myofibroblast which is one of the cancer-associated fibroblasts can be recruited by tumor cells to promote tumor progression and metastasis [21]. Activation of HSCs has been demonstrated to promote HCC progression by generating proinflammatory and proangiogenic microenvironment [29]. In this study, the expression of intratumoral $\alpha \mathrm{SMA}$ was suppressed by Ad-ANGPTL4 treatment. Because $\alpha$ SMA is marker for myofibroblast and activated HSCs, suppression of intratumoral $\alpha$ SMA by Ad-ANGPTL4 indicated its potential to inhibit infiltrated myoblasts and the activation of HSCs. HCC is an inflammation-associated cancer in which infiltrated tumor-associated macrophages (TAMs) play critical roles in tumor microenvironment to promote tumorigenesis and progression through secreting cytokines, chemokines and growth factors [30]. MMP-12 which is a proinflammatory factor mainly produced by macrophages is overexpressed in HCC [31]. In our study, the number of infiltrated TAMs was reduced by Ad-ANGPTL4 treatment along with the suppression of MMP-12 expression. Moreover, administration of rANGPTL4 protein could alter the secretions of cytokines from macrophages, indicating its ability to influence the activity of macrophages. Therefore, these results suggested that ANGPTL4 may suppress HCC progression and metastasis through deterioration of tumor-favorable microenvironment. The direct effects and mechanisms of ANGPTL4 on regulating tumor microenvironment of $\mathrm{HCC}$ are needed further investigation.

In summary, our data demonstrated that ANGPTL4 mRNA was commonly underexpressed in HCC. Downregulation of ANGPTL4 mRNA in HCC was significantly associated with advanced HCC stage, presence of venous infiltration, higher AFP level, poor differentiation, appearance of tumor recurrence, and poor postoperative overall and disease-free survivals of HCC patients. Most importantly, ANGPTL4 treatment could suppress HCC progression and metastasis through promotion of tumor apoptosis, inhibition of tumor motility and angiogenesis, and disruption of tumor-favorable microenvironment. Taken together, our data suggested that ANGPTL4 may be a potential prognostic biomarker and therapeutic agent for patients with advanced HCC.

\section{Materials and methods Patients}

Paired tumor and non-tumor liver tissues were recruited from $110 \mathrm{HCC}$ patients undergone liver resection. Paired primary and recurred tumor and non-tumor liver tissues were recruited from $5 \mathrm{HCC}$ patients. Twenty-six normal liver tissues were recruited. The HCC patients were received operation in the Department of Surgery, Queen Marry Hospital, the University of Hong Kong, from December 1999 and October 2007. The study was approved by the Ethics Committee of the University of Hong Kong.

\section{Cell lines}

A human normal liver cell line named MIHA, 4 human HCC cell lines including HepG2, Huh7, PLC and Hep3B, and a mouse macrophage cell line named Raw264.7 were purchased from American Type Culture Collection. Two human metastatic HCC cell lines, MHCC97L and $\mathrm{MHCC} 97 \mathrm{H}$, were the kind gifts from Liver Cancer Institute, Fudan University, Shanghai, China. The cell lines were maintained in Dulbecco's modified Eagle's medium (DMEM) with high glucose (Invitrogen) supplemented with $10 \%$ heat-inactivated fetal bovine serum (Invitrogen), $100 \mathrm{mg} / \mathrm{ml}$ penicillin $\mathrm{G}$ and $50 \mu \mathrm{g} / \mathrm{ml}$ streptomycin (Invitrogen) at $37^{\circ} \mathrm{C}$ in a humidified atmosphere containing $5 \% \mathrm{CO}_{2}$. MHCC97L cell line stably labeled with the luciferase gene, named MHCC97L-Luc [32], was used for in vivo study.

\section{Orthotopic xenograft nude mice liver tumor model}

Male athymic nude mice (BALB/c-nu/nu, $4-6$ weeks old) were used. Approximately $6 \times 10^{5}$ MHCC97L-Luc cells in $0.2 \mathrm{ml}$ of culture medium were injected subcutaneously in the nude mouse. When the subcutaneous tumor nodule reached $0.8-1 \mathrm{~cm}$ in diameter, it was removed and cut into cubes about $1-2 \mathrm{~mm}^{3}$ in size, which were then implanted into the left liver lobes of another group of nude mice, using the method described previously [32,33]. Then, full-length ANGPTL4-overexpressing 


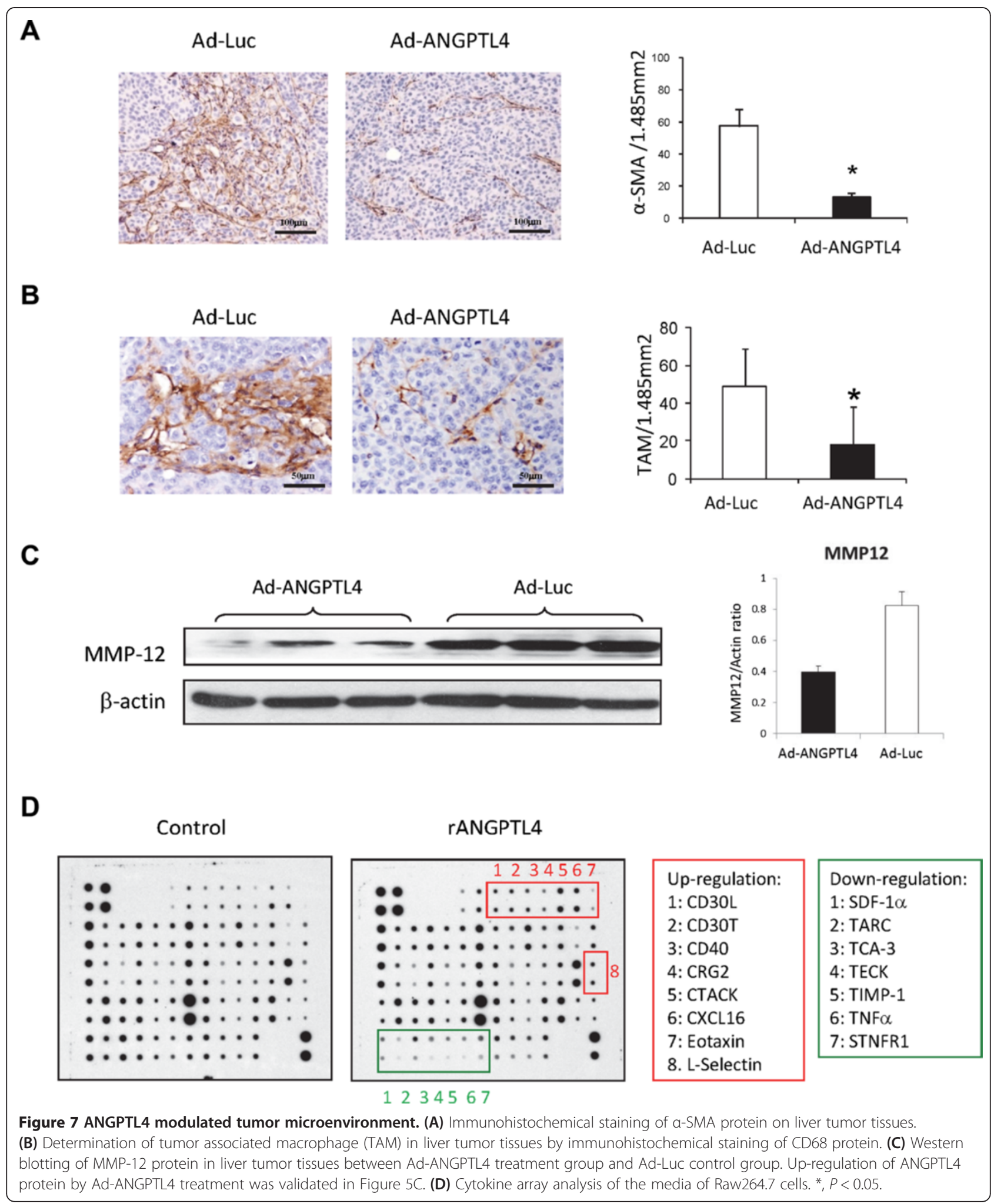

adenovirus (Ad-ANGPTL4 treatment group) or Luciferaseoverexpressing adenovirus (Ad-Luc control group) was injected into the portal vein of each mouse $\left(10^{8} \mathrm{IU} /\right.$ mouse). The size of the in vivo liver tumor and lung metastasis were monitored by Xenogen IVIS ${ }^{\odot}$ imaging system every week. The mice were sacrificed at 6-weeks after implantation. Six mice were performed for each group. Animal study was approved by Animal (Control of 
Experiments) Ordinance Chapter 340, the Department of Health, Hong Kong Special Administrative Region (Ref.: (11-371) in DH/HA\&P/8/2/3 Pt. 29).

\section{Real-time quantitative RT-PCR (qRT-PCR)}

Total RNA from cells and liver tissues were purified by TriZol Regent (Invitrogen). The quality of RNAs was analyzed by Nanodrop 1000 analyzer (Thermo Scientific) and RNA gel electrophoresis. Method of qRT-PCR analysis was described as in previous study [31]. The expression level of $18 \mathrm{~S}$ ribosomal RNA and beta-actin was used as the internal control for clinical samples [31,34] and cells, respectively. Primers used in this study included human ANGPTL4 gene, sense: 5'-TGACCTCAGATGGAGGC TGGACA-3', antisense: 5'-CAGCCAGAACTCGCCG TGGG-3'; 18S ribosomal RNA, sense 5'-CTCTTAGCT GAGTGTCCCGC-3', antisense 5' -CTGATCGTCTTC GAACCTCC-3'; human beta-actin gene, sense: 5'-CTC TTCCAGCCTTCCTTCCT-3', antisense: 5'-AGCACTG TGTTGGCGTACAG-3'. The relative expression level of ANGPTL4 mRNA for each clinical sample was calculated as: $\triangle \triangle \mathrm{Ct}\left(A N G P T L 4_{\text {sample }}\right)=\Delta \mathrm{Ct}\left(A N G P T L 4_{\text {calibrator }}\right)-\Delta \mathrm{Ct}$ $\left(A N G P T L 4_{\text {sample }}\right)$, where $\triangle \mathrm{Ct}\left(A N G P T L 4_{\text {calibrator }}\right)=\mathrm{Ct}(A N$ GPTL4 calibrator $)-\mathrm{Ct}\left(18 \mathrm{~S}_{\text {calibrator }}\right) ; \Delta \mathrm{Ct}\left(A N G P T L 4_{\text {sample }}\right)=$ $\mathrm{Ct}\left(A N G P T L 4_{\text {sample }}\right)-\mathrm{Ct}\left(18 \mathrm{~S}_{\text {sample }}\right)$. The calibrator was defined as the sample whose threshold cycle $(\mathrm{Ct})$ value of ANGPTL4 mRNA was the highest (i.e. sample with the lowest expression level of ANGPTL4 mRNA) among all samples. The relative expression level of ANGPTL4 mRNA was presented as relative fold difference in $\log 2$ base [31,35]. The difference of ANGPTL4 mRNA between tumor and non-tumor tissues of each HCC patient was determined as: $\Delta \Delta \triangle \mathrm{Ct}\left(\right.$ ANGPTL4 $\left._{\text {patient }}\right)=\Delta \Delta \mathrm{Ct}(A N G P$ $\left.T L 4_{\text {tumor }}\right)-\Delta \Delta \mathrm{Ct}\left(A N G P T L 4_{\text {non-tumor }}\right)$. The value of $\Delta \Delta \Delta \mathrm{Ct}$ was equal to $2^{-\Delta \Delta \Delta \mathrm{C}}$ fold change. PCR analysis for each sample was performed in triplicate.

\section{Copy number variation (CNV) analysis}

Ten DNA samples from healthy donors and forty-pairs of DNA samples from tumor and non-tumor tissues of HCC patients were extracted using Qiagen DNA extraction kit (Qiagen). $10 \mu \mathrm{g}$ of each DNA sample was used for CNV analysis by using ANGPTL4 specific TaqMan copy number assay (FAM-labeled, Life Technologies). The RNase P gene (VIC-labeled, Life Technologies) was used as control. The PCR analysis was performed by using TaqMan Universal Master Mix II (Life Technologies) and analyzed in the ViiA7 Real Time PCR system (Life Technologies). The relative ANGPTL4 CNV for each sample was determined as $\triangle \triangle \mathrm{Ct}\left(A N G P T L 4_{\text {sample }}\right)=\triangle \mathrm{Ct}\left(A N G P T L 4_{\text {calibrator }}\right)-\Delta \mathrm{Ct}$ $\left(A N G P T L 4_{\text {sample }}\right), \quad$ where $\Delta \mathrm{Ct}\left(A N G P T L 4_{\text {calibrator }}\right)=\mathrm{Ct}$ $\left(A N G P T L 4_{\text {calibrator }}\right)-\mathrm{Ct}\left(\mathrm{RNaseP}_{\text {calibrator }}\right) ; \quad \Delta \mathrm{Ct}(A N G P$ $\left.T L 4_{\text {sample }}\right)=\mathrm{Ct}\left(A N G P T L 4_{\text {sample }}\right)-\mathrm{Ct}\left(\mathrm{RNaseP}_{\text {sample }}\right)$. The calibrator is the sample with the lowest ANGPTL CNV. PCR analysis for each samples was performed in triplicate.

\section{CpG methylation analysis of ANGPTL4 promoter by pyrosequencing}

Forty-pairs of DNA samples were extracted from tumor and non-tumor tissues of HCC patients using Qiagen DNA extraction kit (Qiagen). Each DNA was performed bisulfite conversion by EZ DNA Methylation-Direction KIT (Zymo Research). A predesigned ANGPTL4 PyroMark CpG Assay (Hs_ANGPTL4_01_PM, Qiagen) was purchased for quantification of $\mathrm{CpG}$ methylation of ANGPTL4 promoter. There were $5 \mathrm{CpG}$ sites in the construct. PCR amplification was performed by using PyroMark $^{\oplus}$ PCR Kit (Qiagen). Pyrosequencing analysis was performed by Genome Research Center, The University of Hong Kong. The sequencing data was analyzed by Pyro Q-CpG Software (Biotage). The percentage of methylation $>10 \%$ was defined as positive methylation.

\section{Western blot}

Method of Western blot analysis was described in previous study [36]. The amount of $20 \mu \mathrm{g}$ of total protein from each sample was used for loading. Antibodies including vascular endothelial growth factor (VEGF), ROCK1, Matrix metalloproteinase-12 (MMP-12) and beta-actin antibody were purchased from Santa Cruz Biotechnology (CA). phospho-Raf $($ Ser259), Phospho-MEK1/2, phosophoErk1/2, Bcl-2, cleaved-caspase 7, and cleaved-caspase 9 antibodies were purchased from Cell Signaling Technology. The intensity of Western blot analysis was quantified by Quantity One software (Bio-Rad).

\section{Morphological study by light and transmission electron microscopy}

Liver tumor tissues including non-tumor margin were taken at different time points after tumor implantation for light microscopy with hematoxylin-eosin staining. The specimens were immediately cut into 1-mm cubes and fixed in $2.5 \%$ glutaraldehyde in sodium carcodylate hydrochloride buffer overnight at $4^{\circ} \mathrm{C}$ for electron microscopy section. The sections were then examined under a transmission electron microscope, Philips EM 208 (Koninklijke Philips Electronics N.V., Eindhoven, Netherlands).

\section{Ultrastructural examination by scanning electron microscopy}

Cells treated with or without recombinant ANGPTL4 (rANGPTL4) protein grown on sterile round glass cover slips were fixed with $2.5 \%$ glutaraldehyde in $0.1 \mathrm{M}$ sodium cacodylate- $\mathrm{HCl}$ buffer, $\mathrm{pH} 7.4$, quenched with $0.1 \mathrm{M}$ sucrose/cacodylate solution, and washed in cacolydate buffer. The samples were then post-fixed with $1 \% \mathrm{OsO} 4$ 
in cacodylate buffer. After a cacodylate buffer wash, they were dehydrated through a graded series of ethanol washes, followed by critical point drying using BAL-TEC CPD 030 Critical Point Dryer (BAL-TEC AG, Liechtenstein). The samples were then sputter-coated with a layer of gold using BAL-TEC SCD 005 Sputter Coater (BAL-TEC AG), and visualized using Leica Cambridge Stereoscan 440 SEM (Leica, Cambridge, UK) at an accelerating voltage of $12 \mathrm{kV}$.

\section{Immunohistochemistry}

Paraffin sections were de-waxed in xylene, rinsed in grade alcohol, and rehydrated in water. Then they were placed in citric buffer (pH 6.0) and treated in a microwave oven with high power for 3 minutes and subsequent low power for 10 minutes. Afterwards, the sections underwent blocking with $3 \%$ peroxidase for 20 minutes and $10 \%$ goat serum for 30 minutes. Subsequently, primary antibodies with proper dilution were applied on the sections, which were then incubated at $4^{\circ} \mathrm{C}$ overnight. Following that, secondary antibodies from Dako EnVision ${ }^{\text {Tw }}$ System (DakoCytomation, Glostrup, Denmark) were applied, and the sections were incubated for 30 minutes at room temperature. Signals were developed with DAB substrate solution (DakoCytomation). The sections were finally counter-stained by hematoxylin solution. Primary antibodies used in this study included VEGF (Santa Cruz Biotechnology), alpha smooth muscle actin ( $\alpha$-SMA, DakoCytomation), CD34 (Santa Cruz Biotechnology), and CD68 (BD Biosciences, San Jose, CA, USA).

\section{Determination of microvessel density (MVD)}

MVD of liver tumor tissue sections was evaluated by immunohistochemical staining with CD34 antibody [37]. Any CD34-positive stained endothelial cell or endothelial cell cluster that was clearly separated from adjacent microvessels, tumor cells and connective elements was counted as one microvessel. The mean microvessel count of the five most vascular areas was taken as the MVD, which was expressed as the absolute number of microvessels per $1.485 \mathrm{~mm}^{2}(\times 200$ field $)$.

\section{Terminal deoxynucleotidyl transferase dUTP nick end labeling (TUNEL) assay}

Paraffin sections of liver tumor tissues from the treatment group and the control group were detected for apoptotic cells by In Situ Cell Death Detection Kit (Roche) according to the manufacturer's protocol.

\section{Cytokine array assay}

RAW264.7 cells were seeded onto a 6-well plate and incubated at $37^{\circ} \mathrm{C}$ with $5 \% \mathrm{CO}_{2}$ for 24 hours. Then the cells were treated with DMEM medium containing $2.5 \mu \mathrm{g} / \mathrm{ml}$ of recombinant mouse ANGPTL4 protein (Obtained from
Prof. Aimin Xu, Department of Medicine, the University of Hong Kong) for 24 hours. Cytokine profiling of the medium was analyzed with $\mathrm{RayBio}^{\circ}$ Mouse Cytokine Antibody Array (Cat\# AAM-CYT-3, RayBiotech Inc.) according to manufacturer's instruction.

\section{Immunofluorescent staining}

Cells were fixed with $4 \%$ paraformaldehyde in PBS for $15 \mathrm{~min}$ at room temperature, and permeabilized with $0.5 \%$ Triton X-100 in PBS for 15 min. The cells were blocked with $1 \%$ bovine serum albumin in PBS for 30 minutes and then incubated with rhodamine phalloidin probe (Invitrogen) for $1 \mathrm{~h}$ at room temperature. After 3 washes in PBS, the cells were stained with DAPI at room temperature for 10 minutes. The cells were washed 3 times with PBS and mounted with FluorSave Reagent (Calbiochem). The slides were analyzed by an image analysis system (Eclipse E600, Nikon).

\section{Statistical analysis}

For clinical samples, the associations of ANGPTL4 mRNA with clinicopathological parameters were analyzed by twotailed t-test (Sex, Venous infiltration, differentiation, pTNM staging, cirrhosis, recurrence and hepatitis B surface antigen) or correlation analysis (Age, serum AFP level, tumor size, duration overall survival and duration of disease-free survival). Receiver Operating Characteristic (ROC) curve was generated to analyze the sensitivity and 1-specificity of $\triangle \triangle \triangle \mathrm{Ct}\left(A N G P T L 4_{\text {patient }}\right)$ value to predict $1^{\text {st }}$ year overall survival of $\mathrm{HCC}$ patients after hepatectomy. Youden index was used to determine Non-downregulation group and Downregulation group of HCC patients. The prognostic value of ANGPTL4 mRNA in predicting overall and disease-free survivals of HCC patients after hepatic resection was calculated by Kaplan-Meier analysis with the log-rank test. For disease-free survival analysis, HCC patients under the category of hospital mortality were excluded. Cox proportional hazard regression model was performed with univariable and multivariable analyses to test factors that were significantly associated with the postoperative overall survival and disease-free survival of the HCC patients. For animal study, continuous variables were expressed as median with range. Mann-Whitney $U$ test was used for statistical comparison. Chi-square $\left(x^{2}\right)$ test was used to compare incidence of lung metastasis in the nude mice orthotopic liver tumor model. Calculations were made with SPSS computer software (SPSS Inc., Chicago, IL, USA). $P$ value $<0.05$ was considered to be statistically significant.

\section{Abbreviations}

AFP: Alpha fetoprotein; ANGPTL4: Angiopoietin-like 4; CNV: Copy number variation; HCC: Hepatocellular carcinoma; HSC: Hepatic stellate cell; MVD: Microvessel density; pTNM: Pathologic tumor-node-metastasis; qRT-PCR: Quantitative reverse transcriptase polymerase chain reaction; 
ROC: Receiver operating characteristic; SMA: Smooth muscle actin; TAM: Tumor-associated macrophages; TUNEL: Terminal deoxynucleotidyl transferase dUTP nick end labeling; VEGF: Vascular endothelial growth factor.

\section{Competing interests}

The authors declare that they have no competing interest.

\section{Authors' contributions}

KTN designed the study, performed the experiments, interpreted the results and wrote the manuscript. AX provided the recombinant ANGPTL 4 protein and revised the manuscript for important intellectual content. QC, DYG, ZXL, CKS and JHF performed the experiments and analyzed the results and revised the manuscript for important intellectual content. RTP, STF and CML provided the clinical advice and critically revised the manuscript for important intellectual content. KM designed the study, interpreted the results, wrote the manuscript and critically revised the manuscript. All authors read and approved the final manuscript.

\section{Authors' information}

Kevin Tak-Pan Ng, Qualification: Bsc, MPhil, PhD. Current position: Research Assistant Professor.

Aimin Xu, Qualification: PhD. Current position: Professor.

Qiao Cheng, Qualification: MD, PhD.

Dong Yong Guo Qualification: MD, PhD. Current position: Medical Consultant.

Zophia Xue-Hui Lim Qualification: Bsc, PhD. Current position: Scientist. Chris Kin-Wai Sun Qualification: BSC, PhD. Current position: Research Officer. Jeffrey Hon-Sing Fung Qualification: BSc. Current position: Research Assistant. Ronnie Tung-Ping Poon Qualification: MD, PhD. Current position: Chair Professor.

Sheung Tat Fan Qualification: MD, PhD. Current position: Chair Professor. Chung Mau Lo Qualification: MD. Current position: Chair Professor. Kwan Man, Qualification: MD, PhD. Current position: Professor.

\section{Acknowledgements}

This study was supported by a Small Project Funding from University of Hong Kong (Ref. No.: 200907176073) and in part by the RGC Collaborative Research Fund (Ref. No.: HKU3/CRF/11R) and General Research Fund (Ref. No.: HKU775011M).

\section{Author details}

${ }^{1}$ Department of Surgery and Centre for Cancer Research, LKS Faculty of Medicine, The University of Hong Kong, Room L9-55, Li Ka Shing Faculty of Medicine Building, 21 Sassoon Road, Pokfulam, Hong Kong, SAR, China. ${ }^{2}$ Department of Medicine, LKS Faculty of Medicine, The University of Hong Kong, Room L9-55, Li Ka Shing Faculty of Medicine Building, 21 Sassoon Road, Pokfulam, Hong Kong, SAR, China.

Received: 17 February 2014 Accepted: 19 August 2014 Published: 22 August 2014

\section{References}

1. Jemal A, Bray F, Center MM, Ferlay J, Ward E, Forman D: Global cancer statistics. CA Cancer J Clin 2011, 61:69-90.

2. Zhu AX: Systemic therapy of advanced hepatocellular carcinoma: how hopeful should we be? Oncologist 2006, 11:790-800.

3. Worns MA, Weinmann A, Schuchmann M, Galle PR: Systemic therapies in hepatocellular carcinoma. Dig Dis 2009, 27:175-188.

4. Yau T, Chan P, Epstein R, Poon RT: Evolution of systemic therapy of advanced hepatocellular carcinoma. World J Gastroenterol 2008, 14:6437-6441.

5. Yau T, Chan P, Epstein R, Poon RT: Management of advanced hepatocellular carcinoma in the era of targeted therapy. Liver Int 2009, 29:10-17.

6. Tan MJ, Teo Z, Sng MK, Zhu P, Tan NS: Emerging roles of Angiopoietin-like 4 in human cancer. Mol Cancer Res 2012, 10:677-688.

7. Zhu P, Goh YY, Chin HF, Kersten S, Tan NS: Angiopoietin-like 4: a decade of research. Biosci Rep 2012, 32:211-219.

8. Kersten S, Lichtenstein L, Steenbergen E, Mudde K, Hendriks HF, Hesselink MK, Schrauwen P, Muller M: Caloric restriction and exercise increase plasma ANGPTL4 levels in humans via elevated free fatty acids. Arterioscler Thromb Vasc Biol 2009, 29:969-974.

9. Mandard S, Zandbergen F, van Straten E, Wahli W, Kuipers F, Muller M, Kersten S: The fasting-induced adipose factor/angiopoietin-like protein 4 is physically associated with lipoproteins and governs plasma lipid levels and adiposity. J Biol Chem 2006, 281:934-944.

10. Lu B, Moser A, Shigenaga JK, Grunfeld C, Feingold KR: The acute phase response stimulates the expression of angiopoietin like protein 4. Biochem Biophys Res Commun 2010, 391:1737-1741.

11. Nakayama T, Hirakawa H, Shibata K, Nazneen A, Abe K, Nagayasu T, Taguchi $T$ : Expression of angiopoietin-like 4 (ANGPTL4) in human colorectal cancer: ANGPTL4 promotes venous invasion and distant metastasis. Oncol Rep 2011, 25:929-935.

12. Zhang $H$, Wong CC, Wei H, Gilkes DM, Korangath P, Chaturvedi P, Schito L, Chen J, Krishnamachary B, Winnard PT Jr, Raman V, Zhen L, Mitzner WA, Sukumar S, Semenza GL: HIF-1-dependent expression of angiopoietin-like 4 and L1CAM mediates vascular metastasis of hypoxic breast cancer cells to the lungs. Oncogene 2012, 31:1757-1770.

13. Zhu P, Tan MJ, Huang RL, Tan CK, Chong HC, Pal M, Lam CR, Boukamp P, Pan JY, Tan SH, Kersten S, Li HY, Ding JL, Tan NS: Angiopoietin-like 4 protein elevates the prosurvival intracellular $\mathrm{O} 2(-): \mathrm{H} 2 \mathrm{O} 2$ ratio and confers anoikis resistance to tumors. Cancer Cell 2011, 19:401-415.

14. Ma T, Jham BC, Hu J, Friedman ER, Basile JR, Molinolo A, Sodhi A, Montaner S: Viral G protein-coupled receptor up-regulates Angiopoietin-like 4 promoting angiogenesis and vascular permeability in Kaposi's sarcoma. Proc Natl Acad Sci U S A 2010, 107:14363-14368.

15. Kim SH, Park YY, Kim SW, Lee JS, Wang D, DuBois RN: ANGPTL4 induction by prostaglandin E2 under hypoxic conditions promotes colorectal cancer progression. Cancer Res 2011, 71:7010-7020.

16. Galaup A, Cazes A, Le Jan S, Philippe J, Connault E, Le Coz E, Mekid H, Mir LM, Opolon P, Corvol P, Monnot C, Germain S: Angiopoietin-like 4 prevents metastasis through inhibition of vascular permeability and tumor cell motility and invasiveness. Proc Natl Acad Sci U S A 2006, 103:18721-18726.

17. Li H, Ge C, Zhao F, Yan M, Hu C, Jia D, Tian H, Zhu M, Chen T, Jiang G, Xie H, Cui Y, Gu J, Tu H, He X, Yao M, Liu Y, Li J: Hypoxia-inducible factor 1 alpha-activated angiopoietin-like protein 4 contributes to tumor metastasis via vascular cell adhesion molecule-1/integrin beta1 signaling in human hepatocellular carcinoma. Hepatology 2011, 54:910-919.

18. Zhang H, Wei S, Ning S, Jie Y, Ru Y, Gu Y: Evaluation of TGFbeta, XPO4, elF5A2 and ANGPTL4 as biomarkers in HCC. Exp Ther Med 2013, 5:119-127.

19. Xu A, Lam MC, Chan KW, Wang Y, Zhang J, Hoo RL, Xu JY, Chen B, Chow WS, Tso AW, Lam KS: Angiopoietin-like protein 4 decreases blood glucose and improves glucose tolerance but induces hyperlipidemia and hepatic steatosis in mice. Proc Natl Acad Sci U S A 2005, 102:6086-6091.

20. Narumiya S, Tanji M, Ishizaki T: Rho signaling, ROCK and mDia1, in transformation, metastasis and invasion. Cancer Metastasis Rev 2009, 28:65-76.

21. Hanahan D, Weinberg RA: Hallmarks of cancer: the next generation. Cell 2011, 144:646-674.

22. Guan XY, Fang Y, Sham JS, Kwong DL, Zhang Y, Liang Q, Li H, Zhou H, Trent JM: Recurrent chromosome alterations in hepatocellular carcinoma detected by comparative genomic hybridization. Gene Chromosome Canc 2000, 29:110-116.

23. Okabe H, Ikai I, Matsuo K, Satoh S, Momoi H, Kamikawa T, Katsura N, Nishitai R, Takeyama O, Fukumoto M, Yamaoka Y: Comprehensive allelotype study of hepatocellular carcinoma: potential differences in pathways to hepatocellular carcinoma between hepatitis $B$ virus-positive and -negative tumors. Hepatology 2000, 31:1073-1079.

24. Qin LX, Tang ZY, Ye SL, Liu YK, Ma ZC, Zhou XD, Wu ZQ, Lin ZY, Sun FX, Tian J, Guan XY, Pack SD, Zhuang ZP: Chromosome 8p deletion is associated with metastasis of human hepatocellular carcinoma when high and low metastatic models are compared. J Cancer Res Clin Oncol 2001, 127:482-488

25. Kaneda A, Kaminishi M, Yanagihara K, Sugimura T, Ushijima T: Identification of silencing of nine genes in human gastric cancers. Cancer Res 2002, 62:6645-6650.

26. Hattori N, Okochi-Takada E, Kikuyama M, Wakabayashi M, Yamashita S, Ushijima T: Methylation silencing of angiopoietin-like 4 in rat and human mammary carcinomas. Cancer Sci 2011, 102:1337-1343. 
27. Zhu AX, Duda DG, Sahani DV, Jain RK: HCC and angiogenesis: possible targets and future directions. Nat Rev Clin Oncol 2011, 8:292-301.

28. Wysocki PJ: Targeted therapy of hepatocellular cancer. Expert Opin Investig Drugs 2010, 19:265-274.

29. Coulouarn C, Corlu A, Glaise D, Guenon I, Thorgeirsson SS, Clement B: Hepatocyte-stellate cell cross-talk in the liver engenders a permissive inflammatory microenvironment that drives progression in hepatocellular carcinoma. Cancer Res 2012, 72:2533-2542.

30. Capece D, Fischietti M, Verzella D, Gaggiano A, Cicciarelli G, Tessitore A, Zazzeroni $F$, Alesse E: The inflammatory microenvironment in hepatocellular carcinoma: a pivotal role for tumor-associated macrophages. Biomed Res Int 2013, 2013:187204

31. Ng KT, Qi X, Kong KL, Cheung BY, Lo CM, Poon RT, Fan ST, Man K: Overexpression of matrix metalloproteinase-12 (MMP-12) correlates with poor prognosis of hepatocellular carcinoma. Eur J Cancer 2011, 47:2299-2305.

32. Sun CK, Man K, Ng KT, Ho JW, Lim ZX, Cheng Q, Lo CM, Poon RT, Fan ST: Proline-rich tyrosine kinase 2 (Pyk2) promotes proliferation and invasiveness of hepatocellular carcinoma cells through c-Src/ERK activation. Carcinogenesis 2008, 29:2096-2105.

33. Man K, Ng KT, Xu A, Cheng Q, Lo CM, Xiao JW, Sun BS, Lim ZX, Cheung JS, Wu EX, Sun CK, Poon RT, Fan ST: Suppression of liver tumor growth and metastasis by Adiponectin in nude mice through inhibition of tumor angiogenesis and downregulation of Rho Kinase/IFN-inducible protein 10/Matrix metalloproteinase 9 signaling. Clin Cancer Res 2010, 16:967-977.

34. Ng KT, Man K, Sun CK, Lee TK, Poon RT, Lo CM, Fan ST: Clinicopathological significance of homeoprotein Six 1 in hepatocellular carcinoma. Br J Cancer 2006, 95:1050-1055.

35. Ng KT, Lo CM, Guo DY, Qi X, Li CX, Geng W, Liu XB, Ling CC, Ma YY, Yeung WH, Shao Y, Poon RT, Fan ST, Man K: Identification of transmembrane protein 98 as a novel chemoresistance-conferring gene in hepatocellular carcinoma. Mol Cancer Ther 2014, 13:1285-1297.

36. Ng KT, Guo DY, Cheng Q, Geng W, Ling CC, Li CX, Liu XB, Ma YY, Lo CM, Poon RT, Fan ST, Man K: A garlic derivative, S-allylcysteine (SAC), suppresses proliferation and metastasis of hepatocellular carcinoma. PLOS ONE 2012, 7:e31655.

37. Poon RT, Ng IO, Lau C, Yu WC, Yang ZF, Fan ST, Wong J: Tumor microvessel density as a predictor of recurrence after resection of hepatocellular carcinoma: a prospective study. J Clin Oncol 2002, 20:1775-1785.

doi:10.1186/1476-4598-13-196

Cite this article as: $\mathrm{Ng}$ et al:: Clinical relevance and therapeutic potential of angiopoietin-like protein 4 in hepatocellular carcinoma. Molecular Cancer 2014 13:196.

\section{Submit your next manuscript to BioMed Central and take full advantage of:}

- Convenient online submission

- Thorough peer review

- No space constraints or color figure charges

- Immediate publication on acceptance

- Inclusion in PubMed, CAS, Scopus and Google Scholar

- Research which is freely available for redistribution 